\title{
Reconstruction and analysis of temporal and spatial variations in surface soil moisture in China using remote sensing
}

\author{
LU Hui $^{1 *} \&$ SHI JianCheng ${ }^{2}$ \\ ${ }^{1}$ Ministry of Education Key Laboratory for Earth System Modeling, and Center for Earth System Science, Tsinghua University, \\ Beijing 100084, China; \\ ${ }^{2}$ The Institute of Remote Sensing Applications, Chinese Academy of Sciences, Beijing 100101, China
}

Received November 1, 2011; accepted January 10, 2012; published online March 31, 2012

\begin{abstract}
An ensemble method was used to combine three surface soil moisture products, retrieved from passive microwave remote sensing data, to reconstruct a monthly soil moisture data set for China between 2003 and 2010. Using the ensemble data set, the temporal and spatial variations of surface soil moisture were analyzed. The major findings were: (1) The ensemble data set was able to provide more realistic soil moisture information than individual remote sensing products; (2) during the study period, the soil moisture increased in semiarid regions and decreased in arid regions with anoverall drying trend for the whole country; (3) the soil moisture variation trends derived from the three retrieval products and the ensemble data differ from each other but all data sets show the dominant drying trend for the summer, and that most of the drying regions were in major agricultural areas; (4) compared with the precipitation trends derived from Global Precipitation Climatology Project data, it is speculated that climate change is a possible cause for the drying trend in semiarid regions and the wetting trend in arid regions; and (5) combining soil moisture trends with land surface temperature trends derived from Moderate Resolution Imaging Spectroradiomete, the study domain was divided into four categories. Regions with drying and warming trends cover $33.2 \%$, the regions with drying and cooling trends cover $27.4 \%$, the regions with wetting and warming trends cover $21.1 \%$ and the regions with wetting and cooling trends cover $18.1 \%$. The first two categories primarily cover the major grain producing areas, while the third category primarily covers nonarable areas such as Northwest China and Tibet. This implies that the moisture and heat variation trends in China are unfavorable to sustainable development and ecology conservation.
\end{abstract}

surface soil moisture, passive microwave remote sensing, temporal and spatial characteristics, variation trends, China

Citation: $\quad$ Lu H, Shi J C. Reconstruction and analysis of temporal and spatial variations in surface soil moisture in China using remote sensing. Chin Sci Bull, 2012, 57: 2824-2834, doi: 10.1007/s11434-012-5011-8

Drought is considered a major natural disaster in China. Recently, the spatial extent of drought has shown an expanding trend in the primary agricultural regions of North China, especially in the North China Plain, where both the drought severity and drought affected area have showna significant increasing trend. Several consecutive drought events occurred on the North China Plain in or after the 1990s. Among them, the drought event of 1997 and of 1999-2002 were the most prominent. As a result of successive droughts, most parts of the plain suffered a water defi-

*Corresponding author (email: luhui@ $@$ tsinghua.edu.cn) cit for 5-6 years, which in turn caused a huge loss of agriculture and ecological deterioration [1]. In order to mitigate the damage, drought monitoring and disaster assessing is necessary. Currently, droughts are estimated through indices derived from meteorological observations in the Beijing Climate Center [2] which are unable to monitor the agricultural droughts accurately and timely. Contrary to the limitations of meteorological drought indices, soil moisture is closely related to agricultural drought as it is a major water source for crops. Soil moisture also serves as an important indicator for production estimation and is therefore key in agriculture drought monitoring and impact assessment. 
Soil moisture is also an affecting factor in land surface processes, which affect land-atmosphere interactions. Soil moisture distribution at regional or global scales has been the subject of much research in many disciplines such as hydrology, agriculture, meteorology and ecology. The temporal and spatial variation of soil moisture also plays a pivotal role in climate change impact assessment.

The traditional observation system of soil moisture, such as the soil wetness observation network, operated by the China Meteorological Administration, is only able to provide observations at a local scale. This point information is insufficient for research and application at a regional scale, considering the high heterogeneity of soil moisture. Therefore, the numerical simulation, in which meteorological observations and land surface models are employed, became the main approach for studying soil moisture variation. Li et al. [3] analyzed the temporal and spatial variations of soil moisture in China between 1950 and 2008, by running the Community Land Model driven by meteorological station observations. Wang et al. [4] simulated the soil moisture distribution in China between 1950 and 2006 using four land surface models. They adopted an ensemble method to estimate the agricultural drought severities and durations. Ma et al. [5] analyzed the drought trend in North China between 1951 and 2004, using soil wetness data retrieved from monthly precipitation and air temperature data. These numerical simulations revealed the soil moisture distribution and variation characteristics in China over the last 50 years and confirmed that climate change had affected soil moisture in China.

The limitations of the numerical simulation approach such as the simplification of physical processes, the uncertainty in parameters and the biases in atmospheric data are significant. Consequently, the accuracy of simulation results is highly dependent on the quality of the atmospheric data from which the uncertainties and biases were inherited. Unlike model simulations, remote sensing is able to provide land surface soil moisture observationsthat do not rely on atmospheric variables. This independence is important to ensure objectivity of the climate change impact assessment.

In this research, three sets of soil moisture products retrieved from the Advanced Microwave Scanning Radiometers for EOS (AMSR-E) were combined into a new ensemble of soil moisture data. With this ensemble data, the temporal and spatial variations of the surface soil moisture in China between 2003 and 2010 were analyzed. Trends of surface soil moisture data were compared with those of precipitationderived from the Global Precipitation Climatology Project (GPCP) data, to identify the possible causes for the temporal variation of the soil moisture. The soil moisture trends were also combined with those of the land surface temperaturederived from the Moderate Resolution Imaging Spectroradiometer (MODIS) to assess their impacts on the agricultural sustainability and ecological conservation.

\section{Data and methods}

\subsection{Soil moisture products retrieved from AMSR-E}

AMSR-E was launched onboard the Aqua satellite by the National Aeronautics and Space Administration (NASA) in May 2002 and has many advantages compared with former passive radiometers, such as Scanning Multichannel Microwave Radiometer (SMMR) [6] and Special Sensor Microwave Imager (SSM/I) [7]. These advantages include: (1) higher spatial resolution at low frequencies, for example, the spatial resolution is $\sim 60 \mathrm{~km}$ at a $6.9 \mathrm{GHz}$ channel; (2) dual polarization (both vertical and horizontal polarization) and multichannel $(6.9,10.65,18.7,36.5$ and $89 \mathrm{GHz})$ observation; and (3) essentially real time data acquisition [8]. Researchers have developed several algorithms and retrieved many variables, including the surface soil moisture, from the brightness temperature observed by AMSR-E.

NASA, Vrije Universiteit in Amsterdam (VUA) and the Japan Aerospace Exploration Agency (JAXA) operationally release global soil moisture retrievals from AMSR-E. Besides these three institutes, some agencies have also developed AMSR-E soil moisture products, such as the single channel retrieving products by the United States Department of Agriculture [9], and the regression products by the Institute of Applied Physics of the Italian National Research Council [10]. These products were focused on specific case studies and not operationally updated, therefore only the NASA, JAXA and VUA soil moisture products were used in this study.

(i) The VUA AMSR-E soil moisture product. In this product, as the first step, soil temperature was derived from the brightness temperature of the $36.5 \mathrm{GHz}$ channel using an empirical regression function. Following this, the Land Surface Parameter Model (LSPM) [11] was adopted to calculate a Microwave Polarization Difference Index (MPDI, see eq. (1)). Using a nonlinear iteration method, the soil moisture and vegetation water content were optimized to minimize the difference between the simulated MPDI by the LSPM and that calculated from the satellite observations. The VUA algorithm uses the dual polarized channels of either 6.9 or $10.65 \mathrm{GHz}$. The product is maintained by VUA and NASA, and downloadable from the website of Goddard Earth Sciences Data and Information Services Center (http:// disc.sci.gsfc.nasa.gov/).

$$
\mathrm{MPDI}=\frac{T B(V)-T B(H)}{T B(V)+T B(H)},
$$

where $T B(V)$ and $T B(H)$ are the brightness temperatures of the vertical and horizontal polarization channels, respectively.

(ii) The JAXA AMSR-E soil moisture product. Brightness temperature at four channels, i.e. from dual polarized channels at 6.9 and $18.7 \mathrm{GHz}$, were used in the JAXA algorithm [12]. First, a brightness temperature database was 
built based on the simulation of a radiative transfer model [13], in which various combinations of soil moisture, surface temperature and vegetation water content were input. And then MPDI and the Index of Soil Wetness (ISW, see eq. (2)) were derived from the database. A reference table was then generated to relate the MPDI and ISW to the soil moisture and vegetation water content. Finally, the soil moisture and vegetation water content were estimated simultaneously from the reversed reference table using the satellite observations as inputs.

$$
\mathrm{ISW}=\frac{T B(18.7 H)-T B(6.9 H)}{T B(18.7 H)+T B(6.9 H)},
$$

where $T B(18.7 H)$ and $T B(6.9 H)$ represent the brightness temperature at the horizontal polarization channels of 18.7 and $6.9 \mathrm{GHz}$, respectively.

(iii) NASA AMSR-E soil moisture product. This product is based on the algorithm proposed by Njoku et al. $[14,15]$ where a regression method was used to derive soil moisture from the MPDI at 10.7 and $18.7 \mathrm{GHz}$. It is available from the National Snow and Ice Data Center [16]. Due to the limitation of the global regression method, the product contains some big uncertainties in regions outside the United States [17].

These three products have two spatial resolutions: $0.5^{\circ}$ and $0.25^{\circ}$. Soil moisture is available in swath type, daily average and monthly average. Because this research focuses on the regional soil moisture distribution and long term trends, the monthly averaged soil moisture at $0.25^{\circ}$ resolution was selected. The VUA product covers the period from 2003 to 2009 and the JAXA and NASA products cover the period from 2003 to 2010 .

\subsection{Monthly averaged precipitation from GPCP}

The soil moisture variation is closely related to precipitation activities. In this study, the precipitation trend in China was derived from GPCP [18] data for the period 2003-2010. By comparing the precipitation trend with the soil moisture trend, the impacts of precipitation changes on the soil wetness variation can be identified. GPCP version 2.2 was used in this research, downloaded from the National Oceanic and Atmospheric Administration (http://www.esrl.noaa.gov/psd/). The original $1^{\circ}$ resolution data was then downscaled to $0.25^{\circ}$ with a bilinear interpolation method.

\subsection{Land surface temperature from MODIS MYD11C3}

Heat and moisture are two fundamental factors in estimating agricultural productivity and evaluating the ecological environment. In this study, the trends of land surface temperature were combined with those of soil moisture, to identify their impacts on agriculture and ecological systems in China during the study period. The land surface temperature was the MYD11C3 product derived from the Aqua/MODIS observation, downloaded from the United States Geological Survey (http://lpdaac.usgs.gov). The spatial resolution of original data is $0.05^{\circ}$. A boxing average method was adopted to convert it into a $0.25^{\circ}$ land surface data set.

\subsection{Standardization and ensemble analysis}

As shown by Wang et al. [19] a multimodel ensemble approach is able to reduce the bias uncertainty of a single model. This study developed a multiproduct ensemble method to combine the JAXA, NASA and VUA AMSR-E products and the new ensemble data set was used to analyze the temporal and spatial characteristics of surface soil moisture in China.

All three soil moisture products share the same basis, i.e. they are derived from the brightness temperature observations provided by AMSR-E, but due to differences in the radiative transfer models, observation channels, ancillary data sets and retrieving techniques, there are obvious gaps among the three products.

Table 1 lists the statistic values for the three products during the research period. Their ranges, means and standard deviations differ from each other. Consequently, the three products cannot be directly combined; otherwise, the information of one or two products would be overwhelmed by the product with the largest values. To overcome this, the ensemble approach proposed in the present study consists of two steps. Step one is to standardize the three soil moisture products according to eq. (3), as

$$
A^{\prime}=\frac{A-\operatorname{mean}(A)}{\sigma_{A}} \times \sigma_{\mathrm{NASA}}+\text { mean }(\mathrm{NASA}) \text {, }
$$

where $A$ represents the soil moisture of the JAXA or VUAproduct, mean () is the statistical mean, $\sigma$ is the standard deviation and $A^{\prime}$ is the new soil moisture value after the standard processing. Step two is to calculate the average values of the standardized products as the ensemble data. In this study, through standardization, the JAXA and VUA products were re-projected into the statistic space of NASA. This standardization method is commonly used in comparing soil moisture data from different sources [17].

Figure 1 gives an example of the soil moisture before and after standardization. The soil moisture is averaged for the Northeast China region $\left(121^{\circ}-125^{\circ} \mathrm{E}, 45-49^{\circ} \mathrm{N}\right)$. As shown in Figure 1(a), VUA (green line) has the largest values, NASA (blue line) has the smallest ranges, and JAXA (black

Table 1 Statistic values of the three soil moisture products (\%)

\begin{tabular}{lcccc}
\hline & Maximum & Minimum & Mean & Standard deviation \\
\hline VUA & 50.00 & 1.60 & 23.63 & 12.13 \\
JAXA & 59.63 & 2.28 & 9.27 & 8.54 \\
NASA & 19.73 & 6.65 & 11.84 & 3.10 \\
\hline
\end{tabular}



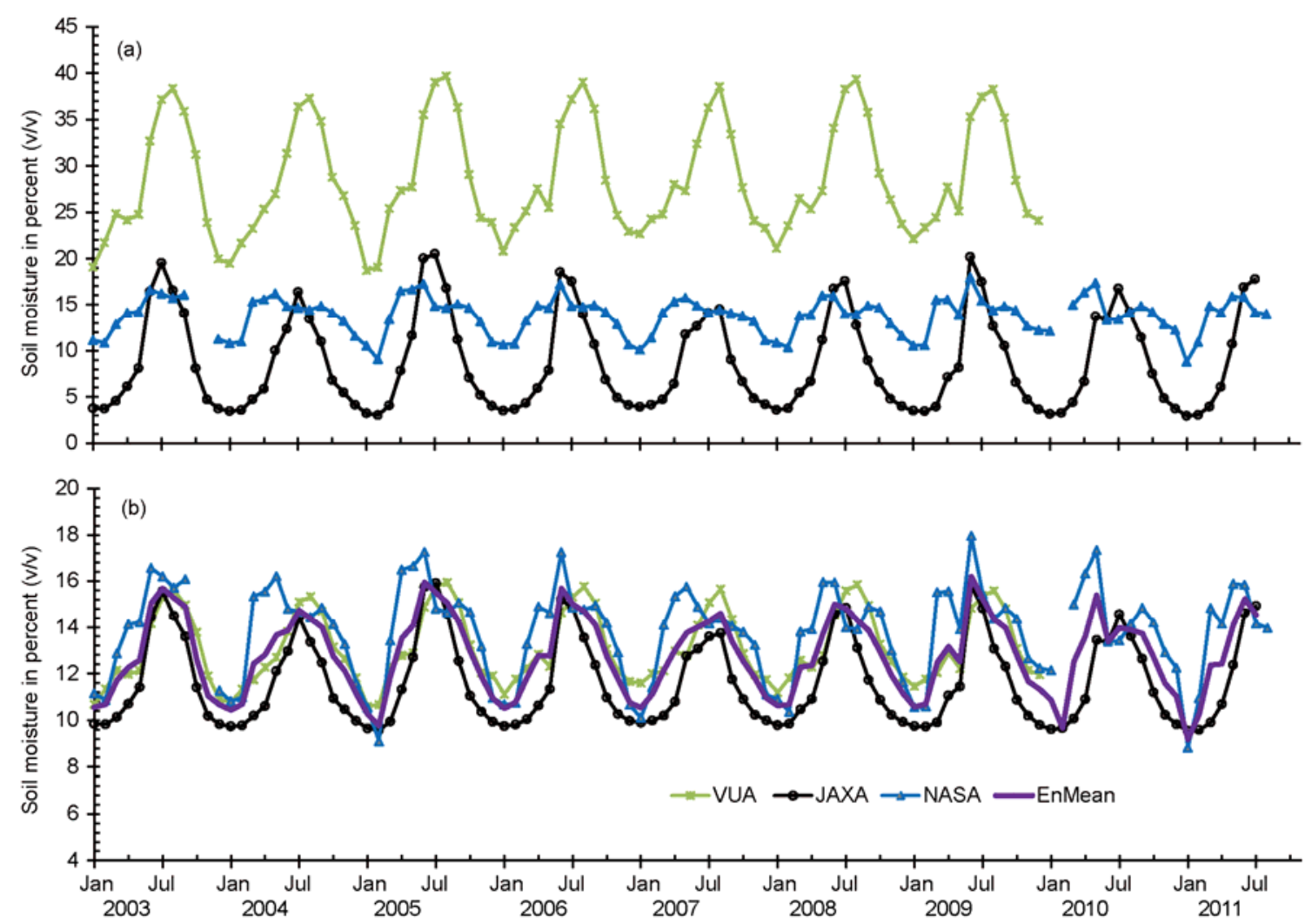

Figure 1 Comparison of soil moisture time series in Northeast China. (a) Original data; (b) tandardized data.

line) has the smallest minimums. If the three products were combined using the original values, much of the information that was born in the JAXA and NASA products would be lost. As shown in Figure 1(b), after standardization, the three products have comparable ranges, peak values and trough values, but do not lose their temporal characteristics. The purple line represents the ensemble data, which was intermediate within the range of the individual products. Comparedwith single products, the systemic biases were reduced by the ensemble approach. For example, the phase bias of NASA was eliminated in the ensemble data, and the missing values of NASA were replaced by the average of the JAXA and VUA products. Additionally, from the results showing in next section, the advantages of the ensemble data are also evident in the spatial distribution.

\subsection{Linear trend analysis}

The linear trends of soil moisture were calculated with a linear regression model [20] in which the surface soil moisture was represented as a linear equation:

$$
\mathrm{SLOPE}=\frac{\sum_{i=1}^{n} s m_{i} \times T_{i}-\left(\sum_{i=1}^{n} s m_{i}\right) \times \frac{\left(\sum_{i=1}^{n} T_{i}\right)}{n}}{\sum_{i=1}^{n} T_{i}^{2}-\frac{\left(\sum_{i=1}^{n} s m_{i}\right)^{2}}{n}},
$$

where $s m$ is the soil moisture in percentage $(\mathrm{v} / \mathrm{v}), b$ is the intercept, and $a$ is the slope, defined as the tendency value, $n$ is the number of years (equal to 8 here); $T_{i}$ is the $i$ th year beginning at 2003; $s m_{i}$ is soil moisture at the $i$ th year. The values of slope represent the trend. If the slope is larger than zero, the soil moisture has wetting trends and if the slope is less than zero it implies a drying trend.

\section{Results}

\subsection{Spatial distribution characteristics of soil moisture}

Figure 2 shows the spatial patterns of standardized soil moisture from three retrieval products for the period 2003-2010. All three products present the same general distribution pattern at the country level: dry in the northwest and wet in the southeast and the northeast plain. However, there are obvious disparities between the different products in that VUA has the largest wet area, while JAXA has the largest dry area.

The distribution pattern shown in the VUA product is more realistic than the other two, considering the climate zone changes from humid to semiarid to arid from southeast to northwest China. However, the VUA product shows a wet region in the southeast of the Tibetan Plateau, which is a high altitude and cold area. This error may be attributed to the empirical regression function for deriving soil temperature from $36.5 \mathrm{GHz}$ brightness temperature, which would 

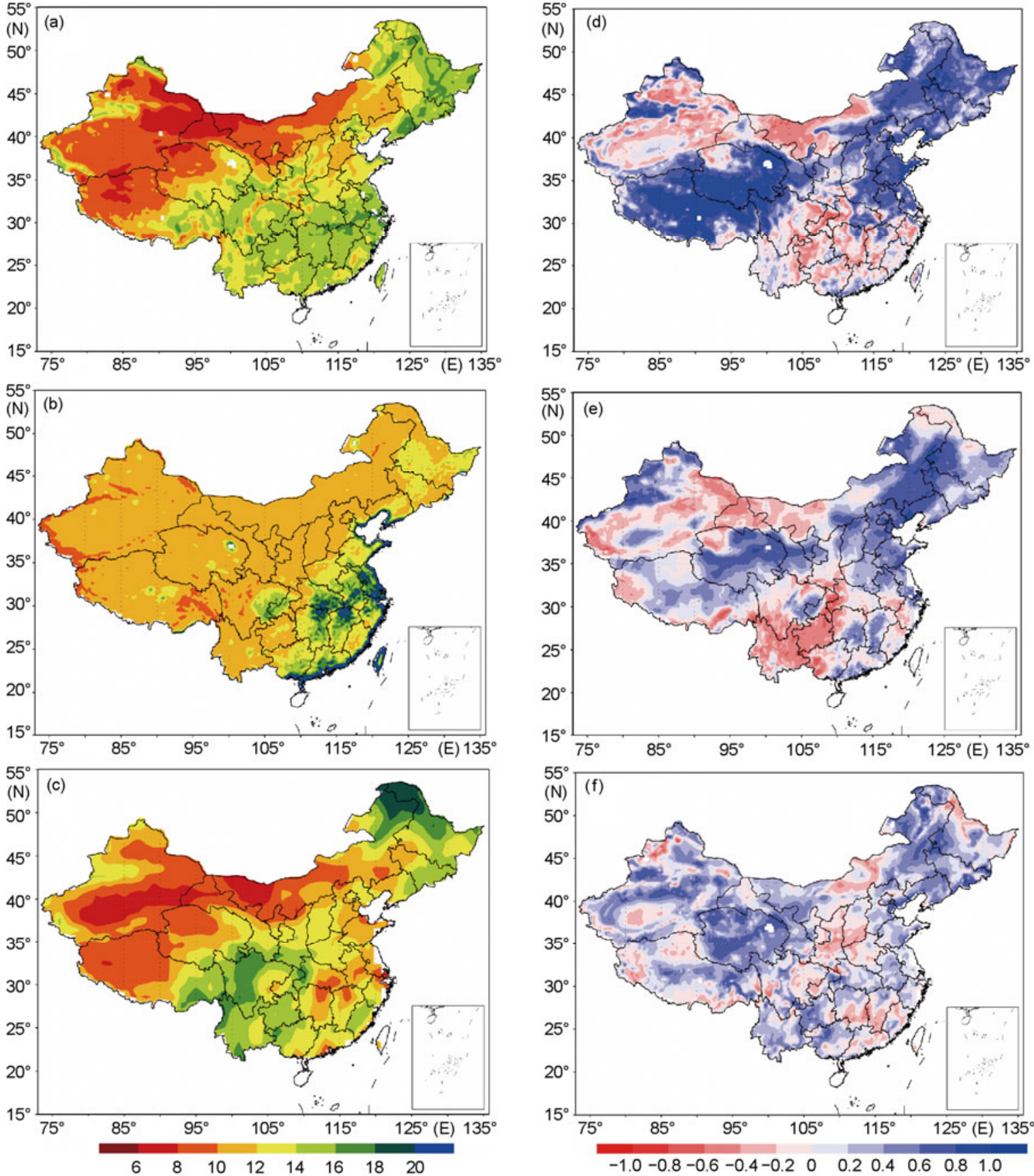

Figure 2 Comparison of averaged spatial patterns of standardized soil moisture (\%; v/v) of VUA (a), JAXA (b) and NASA (c) for the period 2003-2010, and the correlation coefficients between VUA and JAXA (d), JAXA and NASA (e) and VUA and NASA (f).

fail in regions with strong surface heating processes and complicated soil profiles.

The JAXA product shows a drybias over the whole country, but fails to discriminate between the desert and its surrounding in the northwest. The wet areas shown in the JAXA product are mainly located in Sichuan, the middle and lower reaches of Yangtze River and the coastal zones. The transition area from the humid to the arid zone is too narrow to identify. The JAXA product does not show the difference between the arid and semiarid zones. These problems may be due to the use of the reference table from which only the soil moisture value that was used to pre-generate the database can be retrieved.

The dry areas shown in the NASA product are mainly located in the northwest. It also shows the two driest centers in the Tarim desert and the west Inner Mongolia Gobi desert. The NASA product represents the eastern part of the northeast and the southeast part of the Tibetan Plateau as the wet area. The errors in the northeast may be due to the influences of forest, and those in Tibet may be attributed to the 
complex terrain. The surface roughness effects and vegetation water content are represented by the same parameter in the NASA algorithm [14]. This simplification may cause incorrect soil moisture estimation under the complex geological and/or vegetation conditions. Another large bias of the NASA product is located in the middle and lower reaches of the Yangtze River, where it is represented as a dry area by NASA. This error may be due to the use of the global regression method [17], since its coefficients are mainly trained in United States and may be inadequate in China.

The between product correlation coefficients are also shown in Figure 2. Blue indicates two products with similar trends and red represents two products with opposite trends. The area with similar trends is generally larger for all three pairs: $61 \%$ pixels show positive correlation between JAXA and NASA products; $68 \%$ for JAXA and VUA, and $71 \%$ for VUA and NASA.

Figure 3 shows the areas where all three pairs have a positive correlation, including most of the Northeast Plain, the east of Inner Mongolia, the North China Plain, the north part of the Tibetan Plateau, the middle of Gansu and Ningxia, north Xinjiang, most of Jiangsu, and north Anhui. The total area is around $39.3 \%$ of the whole country.

From Figures 2 and 3, it can be concluded that the three products are generally consistent in relative variation but have obvious differences in absolute soil moisture values. Based on the consistency shown in Figures 2 and 3, our ensemble approach is able to combine three products into a new data set, which can provide more realistic soil moisture information for China.

Figure 4 shows the mean annual soil moisture calculated from the ensemble data set. The spatial distribution pattern of soil moisture can be clearly identified. Soil moisture changes from dry to wet from northwest to southeast and northeast. Around $35^{\circ} \mathrm{N}$, there is a transition area. All of these patterns are in agreement with the climate patterns in

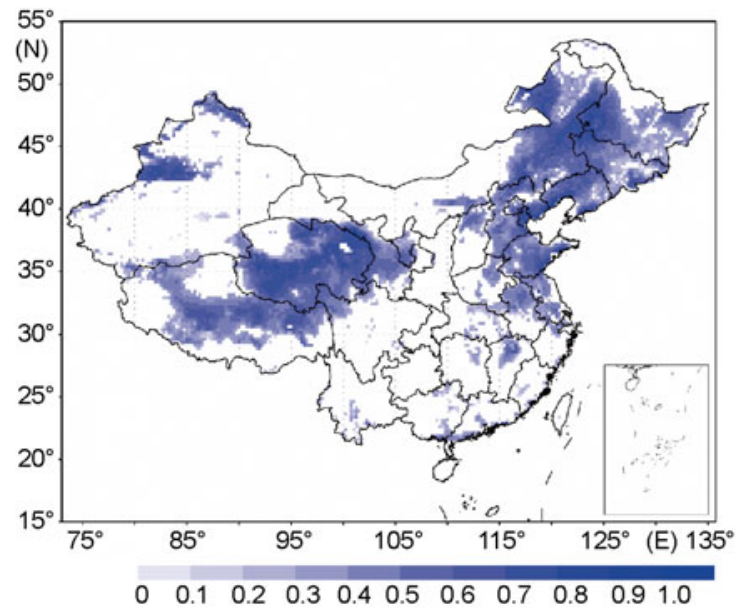

Figure 3 The distribution of mean coefficients where all of three pairs have positive correlations.

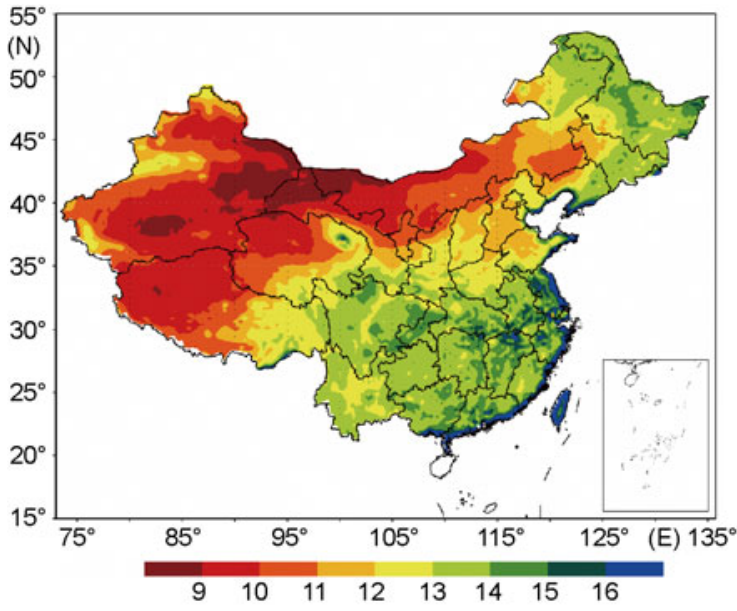

Figure 4 Spatial patterns of averaged annual soil moisture (\%; v/v) of multi-product ensemble data for the period 2003-2010.

China. The ensemble data also corrected the mistakes of the NASA and VUA products in the southeast of Tibet and overcame the limitations of the NASA products in the Yangtze River. The new data set also inherited the merits of individual products, for example, it also showed the two driest centers in the northwest as the NASA product did and showed the wet areas in the Yangtze River, the Northeast Plain and the coastal regions as the VUA and JAXA products did. The ensemble data set also showed some characteristics that are not clear in the individual products. For instance, it represented the wet areas around the Qinghai Lake and the drier area in the Khorchin Desert at the border of Inner Mongolia, Liaoning and Jilin. The spatial patterns of surface soil moisture which were identified from ensemble data set were generally consistent with the results of previous studies in China [3,21].

\subsection{Trend analysis}

By using the linear trend analysis method introduced in section 1.5, the slopes for three retrieval products and ensemble data were calculated, for annual and seasonal soil moisture.

Figure 5(a) shows the annual soil moisture variation trends calculated from the ensemble data for the period 2003-2010. The overall spatial patterns of soil moisture trends were characterized by increases in the northwest and coastal regions in the southeast and decreases in Central China. From a climate zone view, wetting trends were dominant in arid regions which include the north of Inner Mongolia, most of Xinjiang and Qinghai, and west Tibet, while a drying trend appeared in the center of the Tarim Basin. Drying trends prevailed in the semiarid regions which include the Khorchin desert, North China Plain, middle of the Yellow River Basin, and the eastern Tibetan Plateau. The wetting trends in Qinghai and drying trends in East Tibet were consistent with the variation trends of lake surface elevation in Qinghai and Tibet [22]. Parts of humid 

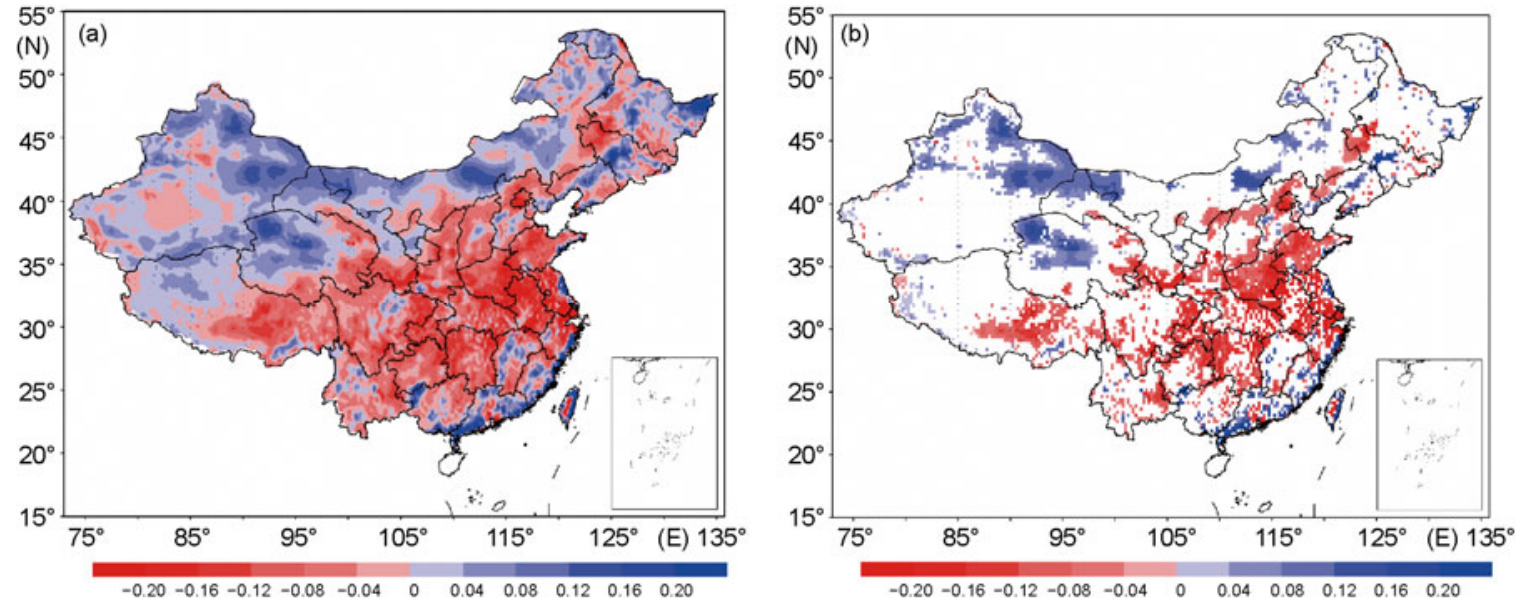

Figure 5 Spatial patterns of annual ensemble soil moisture variation linear trends (a) and those $<10 \%$ significance level for the period $2003-2010$ (b).

regions, including Southwest China and most of the Yangtze River Basin, were characterized by drying trends. The soil moisture in the humid regions of South China, i.e. the coastal regions of Guangdong and Fujian, and parts of Jiangxi had an increasing trend. The trends featured in the arid and semiarid regions are generally in agreement previous studies [3-5]. The drying trend shown in the northeast part of Inner Mongolia is closely related to the expansion of desertification in this region [23].

In this study, the mainland of China consists of 16052 pixels. Among them 8209 pixels (51.1\%) showed drying trends and 7792 pixels (48.5\%) showed wetting trends. For the whole study domain, drying trends were dominant. Thirty-three percent of the total pixels had significant trends (at the $10 \%$ level) with $20 \%$ of pixels significantly drying and $13 \%$ of pixels significantly wetting. As shown in Figure 5(b), the significant drying trends were mainly in the Khorchin Desert, North China Plain, Henan Province, Jianghuai Region, Hanjing Plain, Dongting Lake Plain, and east Tibet. The significant wetting trends were in the northwest of Qinghai, northeast of Xinjiang, and the coastal regions of Guangdong and Fujian.

Annual and seasonal linear trends of the three retrieval products were also calculated. Figure 6 shows the ratios of pixels with drying and wetting trends in annual and seasonal regression during 2003-2010. Only the VUA product showed a dominant wetting trendfor annual linear regression, while the JAXA, NASA and ensemble data sets showed a dominant drying trend. For the NASA product, the drying pixels were always more than the wetting pixels
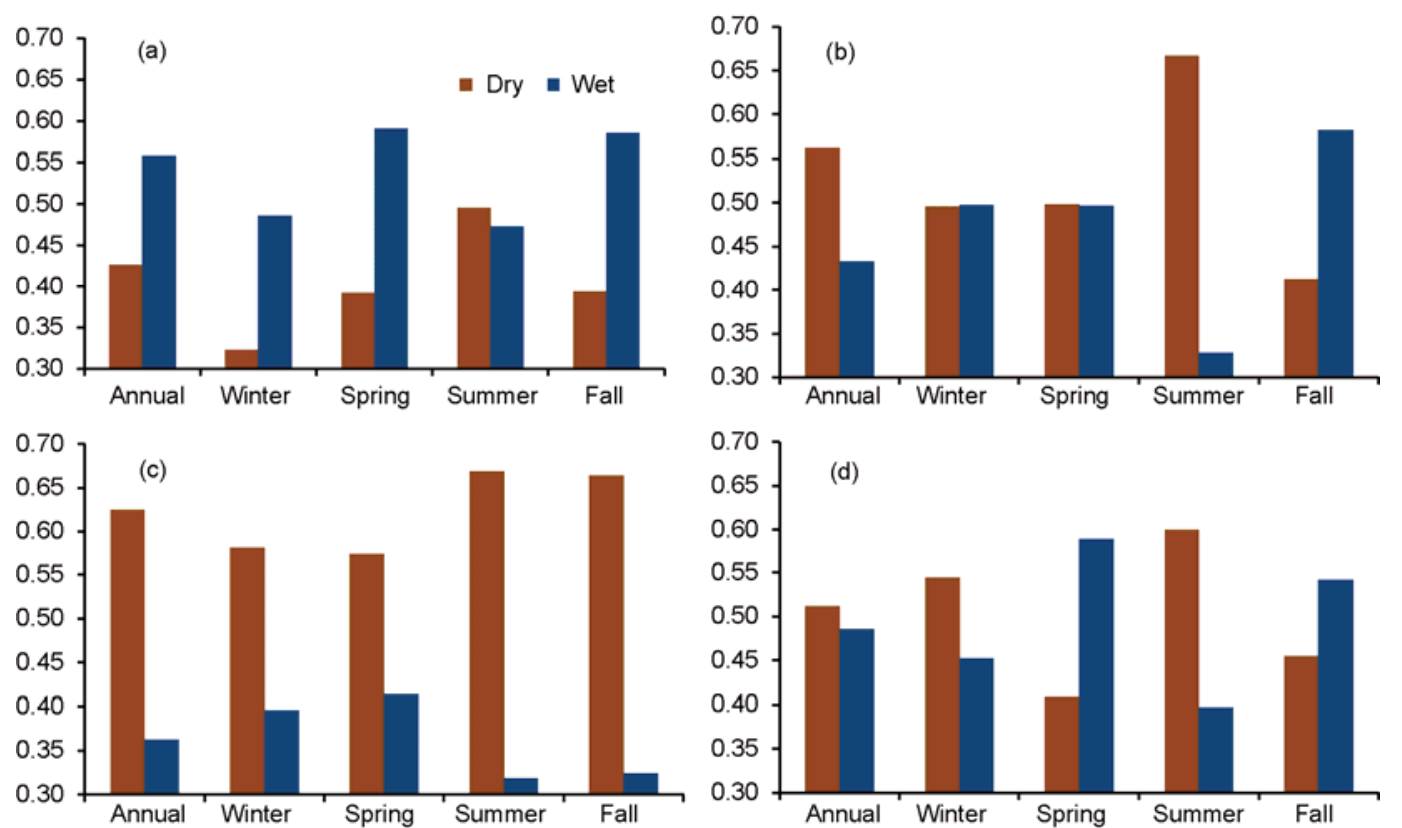

Figure 6 The ratio of pixels with drying trends (brown) and wetting trends (blue) for VUA (a), JAXA (b), NASA (c) and ensemble data (d). 
in all four seasons (Figure 6(c)). In the VUA product, the wetting trend was dominant for all seasons except summer, where a drying trend was dominant (Figure 6(a)). In the JAXA product (Figure 6(b)), the number of pixels with drying and wetting trendswere almost the same for spring and fall, while the drying pixels were much more than the wetting pixels in the summer. As shown in Figure 6(d), the ensemble data set showed dominant wetting trends in spring and fall and dominant drying trends in summer and winter. From Figure 6, it is clear that the three retrieval products generally had different variation trends in both annual and seasonal regressions. However, all of them showed dominant drying trends in summer. This finding implies that the soil moisture was decreasing during the growing season in China between 2003 and 2010.

Figure 7 shows the spatial patterns of soil moisture trends where VUA, JAXA and NASA had the same summer trends. There wasa total of 5418 pixels $(33.8 \%$ of total) in which the three products had the same trends. Among them, soil moisture increased in 1359 pixels (8.5\% of total) and decreased in 4059 pixels $(25.3 \%$ of total). As indicated in Figure 7, all the remote sensing products showed drying trends in the major agriculture regions including the North China Plain, Hetao Plain, Jianghuai Region, Hanjiang Plain and Dongting Lake Plain. This demonstrates that the surface soil moisture in China was generally decreasing in the summer between 2003 and 2010, especially in the major grain production regions.

\subsection{Comparison between precipitation trends and sur- face moisture trends}

Figure 8 shows the correlation coefficients between the monthly GPCP precipitation and the monthly ensemble soil moisture data. There were 10990 pixels (68\% of total) with significant positive correlations $(<5 \%$ significance), and 1225 pixels (10\% of total) with significant negative correlations. The regions with significant positive correlations

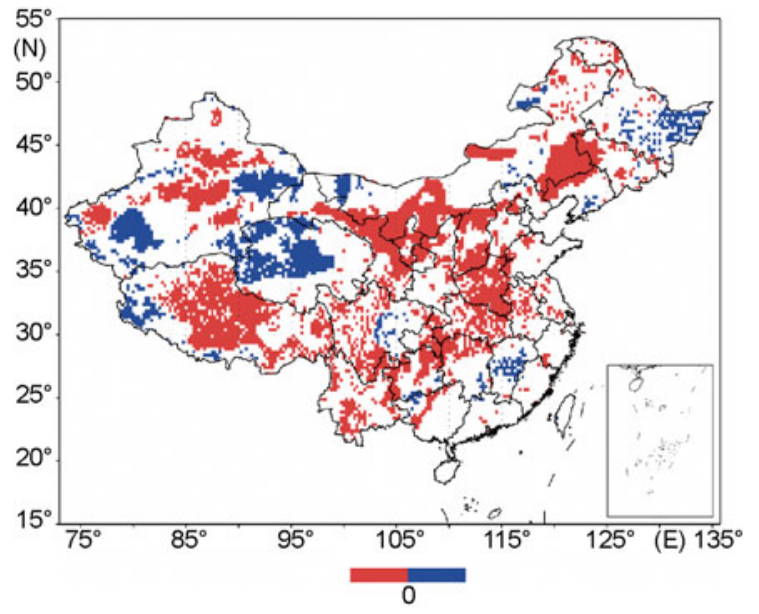

Figure 7 The spatial patterns of soil moisture variation trends where VUA, JAXA and NASA had identical drying (red) or wetting (blue) trends.

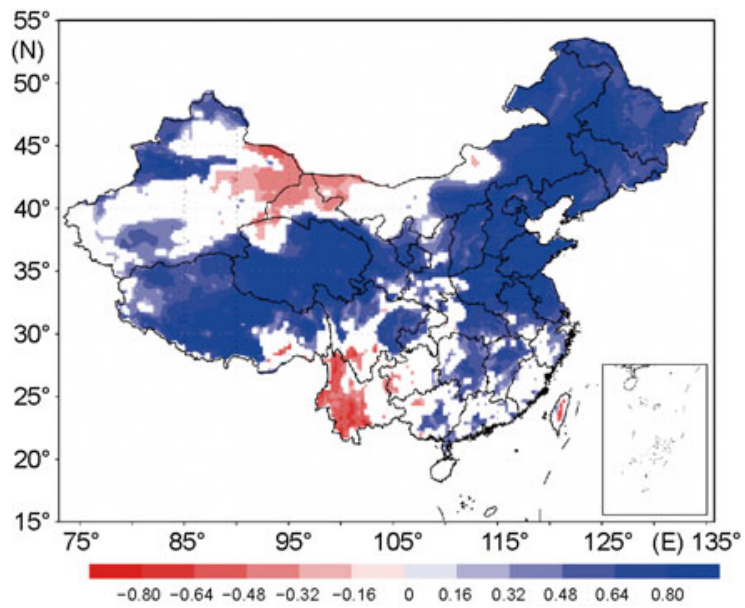

Figure 8 The correlation coefficients of $<5 \%$ significance level between GPCP precipitation and ensemble soil moisture between 2003 and 2010.

were mainly in the Tibetan Plateau, Northeast China, North China Plain, and the Jianghuai Region. This demonstrates that soil moisture variation trends are significantly related to the precipitation variation in these regions. As shown by the red regions in Figure 8, the trends of soil moisture are opposite to those of precipitation in regions such as the west of Yunnan and the border regions of Xinjiang, Inner Mongolia and Gansu.

Figure 9(a) and (b) illustrates the linear trends of precipitation in China from annual mean and summer mean regressions. According to the linear trends, precipitation increased in the humid zones of South China and Southwest regions, and also increased in the arid zones of Qinghai and east Xinjiang. Precipitation decreased in most semiarid zones. Figure 9(c) and (d) shows the distribution characteristics of the pixels in which both precipitation and ensemble soil moisture showed the same trends. Red represents decreasing trends and blue represents the increasing trends. It is clear that surface soil moisture and precipitation was decreasing in the semiarid regions between 2003 and 2010. The increasing precipitation in Qinghai was accompanied with an increase in soil moisture. It suggests that changes in precipitation were possible causes for surface soil moisture variation in these regions. On the contrary, in regions such as Yunnan and Guizhou, surface soil moisture decreased while GPCP precipitation increased and in the boundary areas of Inner Mongolia, Gansu and Xinjiang, surface soil moisture increased while GPCP precipitation decreased. This suggests that although the surface soil moisture variation is largely controlled by precipitation, it is also closely related to radiation, wind speed and air temperature variance, and by human activities resulting in land cover and use changes.

\subsection{Combining analysis of soil moisture trends and land surface temperature trends}

The linear trends of surface temperature were derived 

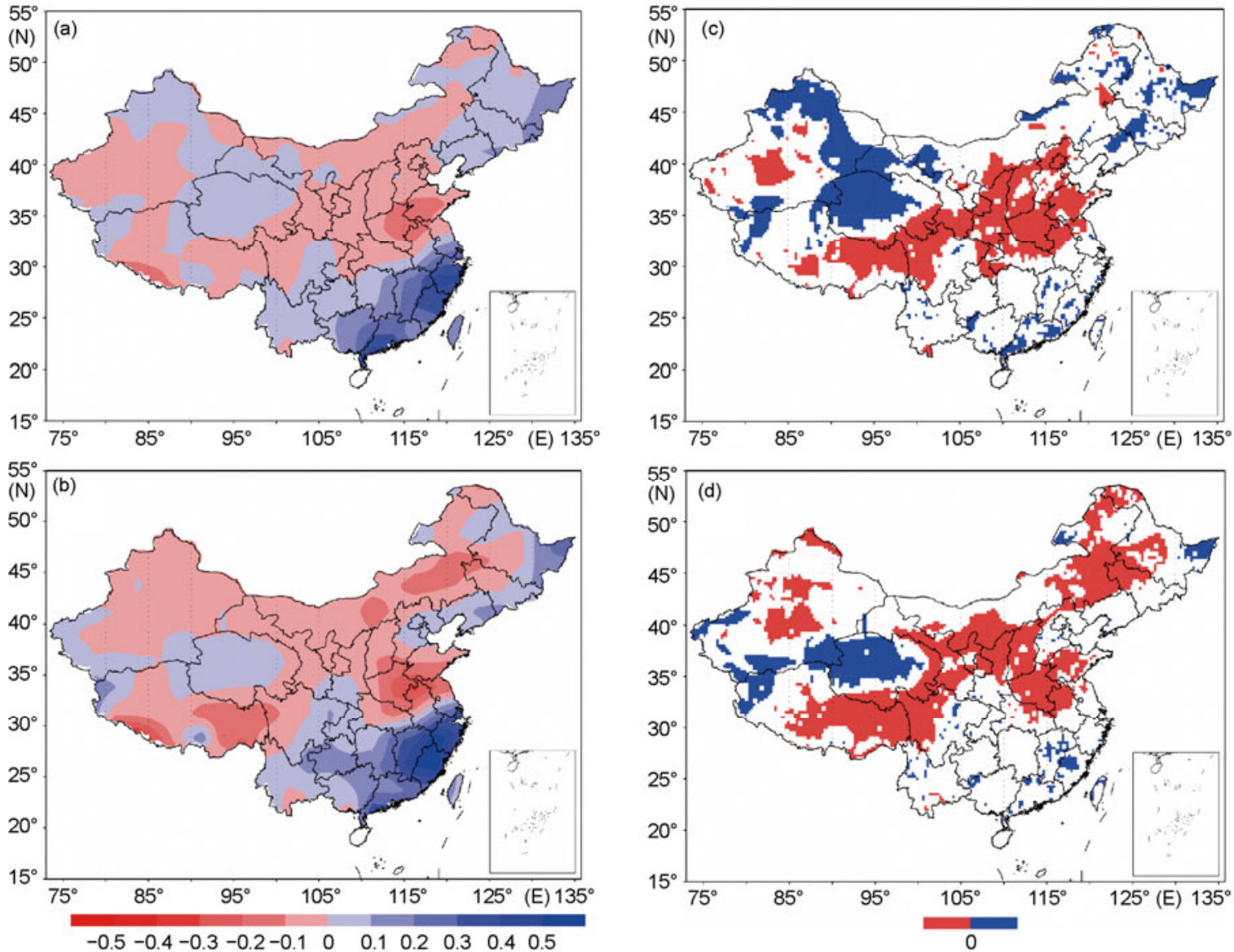

Figure 9 Linear trends of GPCP precipitation between 2003 and 2010 for annual mean regression (a) and summer regression (b). The pattern of variation trends where both GPCP and ensemble soil moisture showed the same trends for annual regression (c) and summer regression (d).

from the monthly land surface temperature product of MODIS between 2003 and 2010. By combing soil moisture trends and land surface temperature trends, the whole research domain was divided into four categories. Figure 10 illustrates the distribution patterns of the four categories for summer regression. The first category has wetting and warming trends (blue); the second category has wetting and cooling trends, (green); the third category has drying and warming trends (yellow); and the forth category has drying and cooling trends (red).

The third and forth categories are unfavorable to agricultural development and ecological systems. The warming effects accelerate evapotranspiration and the drying effects would exacerbate the water shortage and result in agricultural drought. The third category is largely in the south of the Northeast Plain, most of North China, the middle of the Yellow River Basin, the west of the Sichuan Basin, and the east of the Tibetan Plateau. The total area of the third category is $3.18 \times 10^{6} \mathrm{~km}^{2}, 33.2 \%$ of China. The fourth category is largely located in the north of the Northeast Plain and most of South China. Its area is $2.623 \times 10^{6} \mathrm{~km}^{2}, 27.4 \%$ of China. The total area of the third and fourth category covers more than $60 \%$ of China, and are mainly located in the

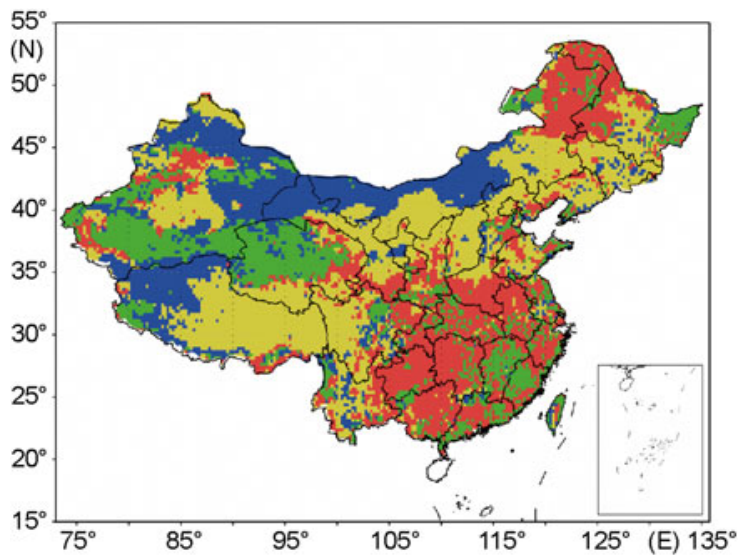

Figure 10 Distribution patterns of the four categories divided according to the combination of soil moisture and land surface temperature trends for the summer between 2003 and 2010.

major grain producing areas. The regions belonging to the first category are favorable to agriculture but are generally non. arable areas including the north of Inner Mongolia, east of Xinjiang, north of Gansu, and northwest of Tibet. The total area of the first category is $2.021 \times 10^{6} \mathrm{~km}^{2}, 21.1 \%$ of China. 


\section{Summary and discussions}

Three sets of soil moisture products retrieved from AMSR-E were used in this study, to analyze the temporal and spatial variations in China between 2003 and 2010. An ensemble approach was proposed to eliminate the differences between the products and to combine the merits of individual products into a new data set. With the reconstructed ensemble soil moisture data, the spatial patterns and temporal variation trends were analyzed. The linear trends of soil moisture were then compared with those of GPCP precipitation and MODIS land surface temperature. The major conclusions were:

(1) Multiproduct ensemble soil moisture data is able to provide more realistic spatial patterns than individual products.

(2) The areas with drying trends (51.1\% of total) were larger than those with wetting trends $(48.5 \%$ of total) between 2003 and 2010. In general, the semiarid regions became drier and arid regions became wetter, consistent with the results from numerical simulations [3-5].

(3) The dominant trends of individual products differ with each other for both annual and seasonal regressions. In summer, the drying trend was dominant for all data sets. Most of the drying regions were in the major agricultural areas of China.

(4) There was a significant correlation between the ensemble soil moisture and GPCP precipitation during the study period. Sixty-eight percent of total pixels had significant positive correlation coefficients. The comparison between precipitation trends and soil moisture trends suggested that climate change was one possible cause for the drying in semiarid regions and the wetting in arid regions.

(5) Through the combination of land surface temperature trends and soil moisture trends, the study domain was divided into four categories. Regions with drying and warming trendscovera $33.2 \%$ area, the regions with drying and cooling trendscover $27.4 \%$, regions with wetting and warming trend cover $21.1 \%$ and regions with wetting and cooling trends cover $18.1 \%$. The first two categories were largely in the major grainproducing areas, while the third category was largely located in nonarable regions such as the Northwest and Tibet. This implies that the moisture and heat variation trend in China is unfavorable to sustainable development and ecology conservation.

As illustrated in Table 1 and Figure 2, there were big gaps between the three retrieval products. The individual products had some obvious systemic biases in some regions. It suggests that the global soil moisture products retrieved from passive microwave remote sensing are not the actual soil moisture values but some relative surface wetness indices $[17,24]$. Both the soil moisture retrieving algorithms and the product generation needs further study.

The soil moisture products used in this study were retrieved from AMSR-E, which cannot provide land surface observations in dense vegetation due to its limited wavelength. Consequently, in forest regions, such as the $\mathrm{Da}$ Hinggan Mountains and Xiao Hinggan Mountains in Northeast China, and the Hengduan Mountains in west Yunnan, the soil moisture retrievals were not reliable. These forest regions were only small portions of the whole study domain, and were not agricultural regions, which were the emphasisof this study. These regions cannot affect the overall temporal and spatial characteristics. As the launch of the Soil Moisture and Ocean Salinity Mission [25] by the European Space Agency and the oncoming Soil Moisture Active and Passive Mission [26] by NASA, L band microwave observation which has a longer wavelength will be available and the shadowing effects of vegetation could be gradually alleviated.

The data used in this study covers the period from 2003 to 2010. The soil moisture spatiotemporal variation characteristics derived from this research are therefore just from a short period of eight years. By integrating the remote sensing observations made by SMMR, SSM/I, Tropical Rainfall Measuring Mission Microwave Imager [27], AMSR-E and oncoming Global Change Observation Mission-Water [28] with the proposed ensemble method, a longterm soil moisture time series beginning in 1978 can be reconstructed. Such a long-term remote sensing data set has high potential in the assessment of global change impacts on water resources, agriculture, and ecology. All the data used in this research was obtained from remote sensing, which makes the results independent from meteorological observations and numerical simulations. The ensemble data set and the results presented in this study could provide complementary information to the traditional climatic analyses.

Authors would like to thank Dr. Fujii at JAXA and Prof. Koike at the University of Tokyo for providing JAXA soil moisture products and Dr. De Jeu for providing VUA soil moisture products. The VUA data used in this effort were acquired as part of the activities of NASA's Science Mission Directorate, and are archived and distributed by the Goddard Earth Sciences (GES) Data and Information Services Center (DISC). This work was supported by the National Natural Science Foundation of China (51109111 and 40930530) and Tsinghua University Initiative Research Program (2011081132)

1 Qin D H. Climate Change: Regional Reasctions and Diseaster Mitigation: The Impacts of Extrem Events and the Coreesponding Solutions Under the Climate Change Background (in Chinese). Beijing: Science Press, 2009

2 Zou X K, Zhang Q, Wang W M, et al. Drought indices and operational drought monitoring in the USA and China (in Chinese). Meteorol Mon, 2005, 31: 6-9

3 Li M X, Ma Z G, Niu G Y. Modeling spatial and temporal variations in soil moisture in China. Chin Sci Bull, 2011, 56: 1809-1820

4 Wang A H, Lettenmaier D P, Sheffield J. Soil moisture drought in China, 1950-2006. J Clim, 2011, 24: 3257-3271

5 Ma Z G, Fu C B.Some evidence of drying trend over north China from1951 to 2004. Chin Sci Bull, 2006, 51: 2913-2925

6 Gloersen P, Barath F T. Scanning multichannel microwave radiometer for Nimbus-G and Seasat-A. IEEE J Oceanic Eng, 1977, 2: $172-178$ 
7 Hollinger J P, Peirce J L, Poe G A. SSM/I instrument evaluation. IEEE Trans Geosci Remote, 1990, 28: 781-790

8 Kawanishi T, Sezai T, Ito Y, et al. The advanced microwave scanning radiometer for the Earth observing system (AMSR-E), NASDA's contribution to the EOS for global energy and water cycle studies. IEEE Trans Geosci Remote, 2003, 41: 184-194

9 Jackson T J. Measuring surface soil moisture ssing passive microwave remote sensing. Hydrol Process, 1993, 7: 139-152

10 Paloscia S, Macelloni G, Santi E. Soil moisture estimates from AMSR-E brightness temperatures by using a dual-frequency algorithm. IEEE Trans Geosci Remote, 2006, 44: 3135-3144

11 Owe M, De Jeu R, Holmes T. Multisensor historical climatology of satellite-derived global land surface moisture. J Geophys Res, 2008, 113: F01002

12 Koike T, Nakamura Y, Kaihotsu I, et al. Development of an advanced microwave scanning radiometer (AMSR-E) algorithm of soil moisture and vegetation water content. Ann J Hydra Eng JSCE, 2004, 48: 217-223

13 Lu H, Koike T, Fujii H, et al. Development of a physically-based soil moisture retrieval algorithm for spaceborne passive microwave radiometers and its application to AMSR-E. J Remote Sens Soc Jpn, 2009, 29: 253-262

14 Njoku E G, Chan S K. Vegetation and surface roughness effects on AMSR-E land observations. Remote Sens Environ, 2006, 100: 190199

15 Njoku E G, Jackson T J, Lakshmi V, et al. Soil moisture retrieval from AMSR-E. IEEE Trans Geosci Remote, 2003, 41: 215-229

16 Njoku E G. AMSR-E/Aqua daily L3 surface soil moisture, interpretive parameters \& QC EASE-Grids V002, 2011. Boulder, Colorado USA: National Snow and Ice Data Center. Digital Media. 2004

17 Draper S C, Wakler J P, Steinle P J, et al. An evaluation of AMSR-E derived soil moisture over Australia. Remote Sens Environ, 2009, 113: 703-710

18 Aberson S D, Sampson C R. On the predictability of tropical cyclone tracks in the Northwest Pacific Basin. Mon Weather Rev, 2003, 131: 1491-1497

19 Wang A H, Bohn T J, Mahanama S P, et al. Multimodel ensemble reconstruction of drought over the continental United States. J Clim, 2009, 22: 2694-2712

20 Wei F Y. Statistic Dignostic and Forecast Technologies in Climatology (in Chinese). Beijing: China Meteorological Press, 2007

21 Zhang W J, Zhou T J, Yu R C. Spatial distribution and temporal variation of soil moisture over China. Part I: Multi-data intercomparison (in Chinese). Chin J Atm Sci, 2008, 32: 581-596

22 Niu Z G, Zhang H Y, Wang X W, et al. Mapping wetlands changes in China between 1978-2008. Chin Sci Bull, 2012, 57: 2813-2823

23 Liu S, Gong P. Change of surface cover greenness in China between 2000 and 2010. Chin Sci Bull, 2012, 57: 2835-2845

24 Liu Y Y, Parinussa R M, Dorigo W A, et al. Developing an improved soil moisture dataset by blending passive and active microwave satellite-based retrievals. Hydrol Earth Syst Sci, 2011, 15: 425-436

25 Kerr Y H, Waldteufel P, Wigneron J P, et al. Soil moisture retrieval from space: The Soil Moisture and Ocean Salinity (SMOS) mission. IEEE Trans Geosci Remote, 2001, 39: 1729-1735

26 Entekhabi D, Njoku E G, O'Neill P E, et al. The Soil Moisture Active Passive (SMAP) mission. P IEEE, 2010, 98: 704-716

27 Jackson T J, Hsu A Y. Soil moisture and TRMM microwave imager relationships in the Southern Great Plains 1999 (SGP99) experiment. IEEE Trans Geosci Remote, 2001, 39: 1632-1642

28 Imaoka K, Shibata A, Kachi M, et al. Status of the GCOM-W and onboard AMSR follow-on instrument. P Soc Photo-Opt Ins, 2006, 6361: U33-U40

Open Access This article is distributed under the terms of the Creative Commons Attribution License which permits any use, distribution, and reproduction in any medium, provided the original author(s) and source are credited. 